\title{
Maternal mental health in Amhara region, Ethiopia: a cross-sectional survey
}

\author{
Joy Noel Baumgartner, ${ }^{a}$ Angela Parcesepe, ${ }^{b}$ Yared Getachew Mekuria, ${ }^{c}$ Dereje Birhanu Abitew, ${ }^{d}$ \\ Wondimu Gebeyehu, ${ }^{\text {e }}$ Francis Okello, ${ }^{f}$ Dominick Shattuckg
}

Poor mental health, including suicidal thoughts, affects a substantial proportion of surveyed women who are up to 2 years postpartum in the Amhara region of Ethiopia. Opportunities for integrating basic psychosocial mental health services into maternal and child health services should be explored.

\section{ABSTRACT}

Background: Postpartum common mental disorders (CMD) such as depression and anxiety are increasingly recognized for their burden in low-resource countries such as Ethiopia. However, the magnitude of postpartum CMD in Ethiopia is not well-established. This short report describes the mental health status of women who had given birth in the last 24 months in the Amhara region of Ethiopia.

Methods: A cross-sectional survey was conducted among 1,319 women aged 15-49 years old who had a delivery in the previous 24 months from 30 randomly selected kebeles (smallest administrative unit in Ethiopia) across Amhara region. The survey included the Self-Reporting Questionnaire (SRQ-20) developed by the World Health Organization-a CMD screening instrument that includes 20 yes/no questions on depression, anxiety, and somatic symptoms experienced in the last 30 days. We used 2 cutoff scores to determine probable cases of mental disorder: (1) 4/5 ( $\leq 4$ "yes" responses=non-case, $\geq 5$ "yes" responses =case) based on a study that validated the SRQ-20 against a diagnostic tool in Butajira, Ethiopia, and (2) a more conservative and commonly used $7 / 8$ cutoff.

Results: Among the 1,294 women who completed the full survey including the SRQ-20,32.8\% had probable CMD using the $4 / 5$ cutoff score versus $19.8 \%$ using the more conservative $7 / 8$ cutoff. About $15 \%$ of the women responded affirmatively that they had had suicidal thoughts.

Conclusion: Poor mental health was common among the surveyed women who had given birth in the past 24 months in Amhara region, Ethiopia. Integrating mental health care into maternal and child health services could potentially alleviate the burden of CMD among women in the extended postpartum period.

\section{INTRODUCTION}

M ental disorders during and after pregnancy are increasingly recognized for their burden in lowand middle-income countries (LMICs) - for both the disability among the affected women and the asso-

${ }^{\text {a }}$ FHI 360, Washington, DC, USA. Now with Duke Global Health Institute at Duke University, Durham, NC, USA.

bUniversity of North Carolina at Chapel Hill, Gillings School of Public Health, Chapel Hill, NC, USA.

${ }^{\circ} \mathrm{FHI}$ 360, Addis Ababa, Ethiopia.

'Bahir Dar University, Bahir Dar, Ethiopia.

e Amhara Regional Health Bureau, Bahir Dar, Ethiopia.

${ }^{f}$ FHI 360, Addis Ababa, Ethiopia. Now with Abt Associates, SHOPS Project, Bethesda, MD

${ }^{9} \mathrm{FHI} 360$, Livelihoods and Food Security Technical Assistance II (LIFT II), Durham, NC, USA.

Correspondence to Joy Noel Baumgartner (joy.baumgartner@duke.edu). ciated impact on their children. ${ }^{1-4}$ A review of studies on postpartum common mental disorders (CMD), which include depression and mixed depressive, anxious, and somatic symptoms, among women in LMICs revealed a weighted mean prevalence of $19.8 \%{ }^{1}$ In Africa, another systematic review found a weighted mean prevalence of $18 \%$ for depression among postpartum women and $14 \%$ for anxiety. ${ }^{2}$ Risk factors for postpartum CMD include poverty, marital status (unmarried), marital conflict, family conflict, higher parity, adverse reproductive health outcomes (eg, unintended pregnancy, pregnancy complications, stillbirth), and lack of social support. ${ }^{1,2}$

The magnitude of postpartum CMD in Ethiopia is not well-established. Estimates for depression during and after pregnancy have ranged from 
$9 \%$ to $20 \%{ }^{9,10}$ and for postpartum CMD, the estimates have been as high as $33 \% .^{11}$ Understanding the postpartum CMD burden is important for informing mental health services and policies.

In order to reach postpartum women suffering from disabling depression, anxiety, or somatic disorders, global guidance promotes integrating mental health services into maternal and child health $(\mathrm{MCH})$ care platforms. ${ }^{5}$ In many contexts, integration must extend beyond facility-based services because many women lack access to such services. For example, in the Amhara region of Ethiopia, $89 \%$ of women deliver at home and 93\% do not receive a postpartum checkup within 41 days after delivery. ${ }^{6}$

To improve access to services for many of the poorest and most remote Ethiopians, the government established the Health Extension Program, which includes a cadre of trained health extension workers (HEWs) who provide communitybased services. ${ }^{7}$ Per government guidelines, HEWs are at least 18 years old, are women (except in pastoralist areas), have at least a 10th grade education, and are nominated and selected at the local level. ${ }^{7}$ Each kebele (smallest administrative unit in Ethiopia, similar to a ward) has 1 health post (lowest level of primary care) with 2 HEWs who provide a variety of health services, including the pregnancy continuum of care. The HEWs conduct home visits, hold community conversations on health topics, and distribute health-related commodities. In theory, they also have mental health training to screen people for mental health problems and refer them for services, and they are tasked with mental health prevention, promotion, and ongoing communitybased care. ${ }^{8}$ Diagnosis and treatment for mental disorders is offered at the next level of care (health centers), staffed by health officers and nurses.

This report describes the mental health status of Ethiopian women up to 2 years postpartum in the Amhara region. The mental health data are from a study undertaken by the Amhara Regional Health Bureau and FHI 360 whose main purpose was to identify factors associated with postpartum family planning use; the study hypothesized that mental health was one such factor but did not find an association between mental health status and postpartum family planning uptake. ${ }^{12}$

\section{METHODS}

A cross-sectional survey was conducted among 1,319 women aged 15-49 years old who had delivered within the previous 24 months, from 30 randomly selected kebeles across Amhara region. Participants were recruited from 3 randomly selected zones, comprising East Gojjam $(n=389)$, South Wollo $(n=385)$, and North Gondar $(\mathrm{n}=390)$, as well as 1 additional zone, Bahir Dar $(n=130)$, which was purposefully selected for urban representation. Data collectors approached local health workers, including HEWs, at the selected kebeles to generate lists of women who had delivered within the last 24 months regardless of whether the delivery took place at a health facility or at home. In addition, the selected women were asked if they knew any other women who had delivered within the last 24 months in their area.

The survey included the Self-Reporting Questionnaire (SRQ-20) developed by the World Health Organization (WHO), which is a CMD screening instrument that includes 20 yes/ no questions on depression, anxiety, and somatic symptoms experienced in the last 30 days. ${ }^{13}$ Each of the 20 questions is scored 0 (no) or 1 (yes), with the total score ranging from 0 to 20; a cutoff score is used to determine probable cases of mental disorder or poor mental health. The SRQ20 has been used extensively in Ethiopia among various populations as well as across Africa. ${ }^{10,14-16}$ For this study, we obtained an Amharictranslated and pretested version of the SRQ-20 from colleagues who used it with a perinatal population. ${ }^{10}$

We received ethical approval from the Protection of Human Subjects Committee at FHI 360 and the Institutional Review Board at the Amhara Regional Health Bureau. Participants provided oral informed consent. All interviews were conducted at participants' homes (usually outside to ensure confidentiality during the interview). Participants who responded affirmatively to the suicidal ideation item or to $\geq 10$ questions were referred to local health services.

A total of 1,294 nonpregnant women who had given birth in the previous 24 months completed the survey including the SRQ-20. We present CMD prevalence estimates using 2 different SRQ-20 cutoff scores. The first is a $4 / 5$ cutoff score (ie, $\leq 4$ "yes" responses $=$ non-case, $\geq 5$ "yes" responses=case), which we selected based on an unpublished study that validated the

\section{About $20 \%$ of postpartum women in developing countries have common mental disorders.}

The WHO Self-Reporting Questionnaire is a simple and commonly used tool to screen for common mental disorders. 
SRQ-20 against a diagnostic tool in antenatal clinics in semi-rural areas around Butajira, Ethiopia. The study found an optimal cutoff score of 5 or more with $80 \%$ sensitivity and specificity (personal communication with Dr. Charlotte Hanlon, Addis Ababa University, 2014 Apr 2). Another study using the SRQ-20 with perinatal women in Ethiopia found conflicting evidence for optimal cutoff scores. ${ }^{10}$ We therefore also present SRQ-20 data using a 7/8 cutoff, which has been commonly used in other studies around the world. ${ }^{18}$ The bivariate association between mental health and relationship status was conducted using Pearson's chi-square test and adjusted for clustering at the kebele level.

\section{RESULTS}

$20 \%$ to $33 \%$ of the surveyed women in Amhara region had poor mental health.

\section{About $15 \%$ of surveyed women had had suicidal thoughts.}

Among the 1,294 surveyed women, 32.8\% had probable CMD using the 4/5 SRQ-20 cutoff score (responding affirmatively to $5+$ items). Using a more conservative cutoff of $7 / 8$ (responding affirmatively to $8+$ items ), $19.8 \%$ had probable CMD.

Probable CMD by zone using the $7 / 8$ cutoff was $24.1 \%$ in North Gondar, 15.2\% in East Gojjam, $19.5 \%$ in South Wollo, and $21.5 \%$ in Bahir Dar.

A sizable proportion of women $(n=187$, or $14.5 \%$ ) responded affirmatively to the question, "Have you thought of ending your life?", indicating the recent burden of suicidal thoughts among this population (Table).

Unmarried women $(n=120$, or $9.3 \%$ of the total sample) were significantly more likely than married women to experience poor mental health $(P<.0001)$. In this sample, unmarried women were primarily widowed, separated, or divorced.

Internal reliability of the SRQ-20 was excellent (Cronbach's alpha $=0.92$ ).

\section{DISCUSSION}

This study highlights the substantial levels of mental distress and probable CMD among the surveyed women who had delivered in the past 24 months in Amhara region, Ethiopia, including unmarried women. A recent review of CMD prevalence studies conducted in Ethiopia reveals that depression and the broader category of CMD have been measured with a range of instruments in various populations, making specific contextual comparisons challenging. ${ }^{19}$ Our estimates are somewhat higher than those from other studies in Ethiopia conducted among women of reproductive age and among the general population, suggesting that women up to 2 years postpartum may potentially be at elevated risk of CMD compared with a general population of women of reproductive age. ${ }^{19,20}$ More research is needed, however, to explore this potential relationship further since several limitations with the study design limit our ability to draw firm conclusions. Furthermore, it is worth reiterating that the SRQ-20 captures a range of mental distress symptoms, more inclusive than depression alone. Nonetheless, it is clear that a substantial proportion of women in this study were experiencing mental health problems, including suicidal thoughts, for which services are urgently needed.

The global health field has called for integrating mental health care into priority health care platforms, and specifically for integrating maternal mental health care into MCH services. ${ }^{5,21}$ Given the low rates of facility-based postpartum checkups in Amhara region and nationally, access to HEWs for mental health prevention activities and referral for more serious mental health problems during the extended postpartum period is vital. Ethiopia's national mental health strategy mandates the integration of mental health services into the primary health care system, and it emphasizes self-care and use of HEWs for promotion and prevention activities to increase awareness, reduce stigma, and increase use of mental health services. ${ }^{8}$ Given the high rates of probable CMD among women up to 2 years postpartum, mental health services could potentially be integrated into $\mathrm{MCH}$ services offered by providers based at local health posts and/or by HEWs, such as at childhood immunization and well-child visits. The possibility of HEWs providing simple psychosocial interventions, such as screening for maternal mental distress, basic counseling, and facilitating establishment of support groups, could be further explored and tested in Ethiopia. ${ }^{22}$

\section{Limitations}

This study used a convenience sample of women identified through local health care providers, which excluded very remote communities that could not be reached by vehicle, and therefore may not be representative of the entire Amhara region. Also, while our focus was on mental distress in the postpartum period, which is usually defined as the first 12 months after childbirth, our sample consisted of women who 
TABLE. SRQ-20 Results for Probable Mental Disorder/Poor Mental Health in the Past 30 Days Among Women With a Delivery in the Past 24 Months, by Relationship Status, Amhara Region, Ethiopia

\begin{tabular}{lccc}
\hline SRQ-20 Questions & Total Sample & Married & Unmarried \\
$(\mathbf{n}=1,174)$ & $120)$ \\
\hline
\end{tabular}

No. responding "yes" (\%)

1. Been nervous, tense, or worried

2. Frightened easily

3. Generally felt unhappy

4. Found it difficult to make decisions

5. Had headaches quite often

6. Had problems thinking clearly

7. Found it difficult to enjoy daily activities

8. Often lost interest in things

9. Felt tired easily

10. Experienced loss of appetite

11. Problems with sleep

12. Had uncomfortable feelings in stomach

13. Often experienced shaking of hands

14. Felt tired all the time

15. Cried more than usual

16. Daily activities suffered

17. Thought of ending life

18. Felt unable to play a useful part in life

19. Experienced poor digestion

20. Felt worthless

$\begin{array}{lll}320(24.8) & 271(23.1) & 49(40.8) \\ 265(20.5) & 236(20.1) & 29(24.2) \\ 247(19.2) & 203(17.4) & 44(37.0) \\ 149(11.5) & 120(10.2) & 29(24.2) \\ 519(40.1) & 466(39.7) & 53(44.2) \\ 204(15.8) & 174(14.9) & 30(25.2) \\ 186(14.4) & 146(12.5) & 40(33.3) \\ 152(11.8) & 117(10.0) & 35(29.2) \\ 402(31.1) & 355(30.3) & 47(39.2) \\ 312(24.2) & 287(24.5) & 25(21.0) \\ 278(21.6) & 243(20.8) & 35(29.4) \\ 310(24.0) & 282(24.1) & 28(23.3) \\ 139(10.8) & 126(10.8) & 13(10.9) \\ 359(27.8) & 37(30.8) \\ 194(15.1) & 322(27.5) & 35(29.2) \\ 140(10.8) & 159(13.6) & 22(18.5) \\ 187(14.5) & 118(10.1) & 33(27.5) \\ 170(13.2) & 154(13.2) & 23(19.2) \\ 258(19.9) & 147(12.6) & 38(31.7) \\ 160(12.4) & 220(18.7) & 31(25.8) \\ & 129(11.0) & \end{array}$

$320(24.8)$

$265(20.5)$

$247(19.2)$

204 (15.8)

$186(14.4)$

$152(11.8)$

$2(31.1)$

$78(21.6)$

$359(27.8)$

$194(15.1)$

$140(10.8)$

$160(12.4)$
$27123.1)$

$29(24.2)$

$53(44.2)$

$30(25.2)$

40 (33.3)

(29.2)

(39.2)

$5(21.0)$

$(29.4)$

$13(10.9)$

$37(30.8)$

$35(29.2)$

18.5

Abbreviation: SRQ, Self-Reporting Questionnaire.

All variables had $\leq 6$ missing responses. Percentages are based on non-missing data. had delivered within the past 24 months, which limits our ability to associate the mental distress estimates within the conventionally defined postpartum period. Our ability to draw firm conclusions about the occurrence of CMD specifically within the postpartum period is further limited because the study did not include a comparison group of women who had not given birth. However, the sample of women who were up to 24 months postpartum represents an extended postpartum period, and thus the estimates from this study add to the literature on maternal CMD.

Acknowledgments: We thank Yanwu Zeng, Mario Chen, and John Stanback for their thoughtful reviews of earlier drafts.

Financial support was provided to FHI 360 by the United States Agency for International Development (USAID) under the terms of Cooperative Agreement GPO-A-00-08-00001-00 for the Program Research for Strengthening Services (PROGRESS) project. The views and opinions expressed in this paper are those of the authors and do not necessarily reflect the views and opinions of USAID.

Competing Interests: None declared. 


\section{REFERENCES}

1. Fisher J, Cabral de Mello M, Patel V, Rahman A, Tran T, Holton $S$, et al. Prevalence and determinants of common perinatal mental disorders in women in low- and lower-middle-income countries: a systematic review. Bull World Health Organ. 2012;90(2):139G-149G. CrossRef. Medline

2. Sawyer A, Ayers S, Smith H. Pre- and postnatal psychological wellbeing in Africa: a systematic review. J Affect Disord. 2010;123(1-3):17-29. CrossRef. Medline

3. Hanlon C. Maternal depression in low- and middle-income countries. Int Health. 2013;5(1):4-5. CrossRef. Medline

4. Stewart RC. Maternal depression and infant growth? A review of recent evidence. Matern Child Nutr. 2007;3(2):94-107. CrossRef. Medline

5. Rahman A, Surkan PJ, Cayetano CE, Rwagatare P, Dickson KE. Grand challenges: integrating maternal mental health into maternal and child health programmes. PLoS Med. 2013;10(5):e1001442. CrossRef. Medline

6. Central Statistical Agency [Ethiopia]; ICF International. Ethiopia demographic and health survey 2011. Addis Ababa (Ethiopia): Central Statistical Agency; 2012. Co-published by ICF International. Available from: http://dhsprogram.com/pubs/ pdf/FR255/FR255.pdf

7. Bilal N. Health Extension Program: an innovative solution to public health challenges of Ethiopia - a case study. Bethesda (MD): Abt Associates, Health Systems 20/20; 2012. Available from: http://www.healthsystems2020.org/content/resource/ detail/85866/

8. Federal Democratic Republic of Ethiopia, Ministry of Health (MOH). National mental health strategy: 2012/13-2015/16. Addis Ababa (Ethiopia): $\mathrm{MOH} ; 2012$. Available from: http:// www.prime.uct.ac.za/images/prime/Ethiopia_MH_Strategy_ 2012-2016.PDF

9. Dibaba Y, Fantahun M, Hindin MJ. The association of unwanted pregnancy and social support with depressive symptoms in pregnancy: evidence from rural Southwestern Ethiopia. BMC Pregnancy Childbirth. 2013;13:135. CrossRef. Medline

10. Hanlon C, Medhin G, Alem A, Araya M, Abdulahi A, Hughes M, et al. Detecting perinatal common mental disorders in Ethiopia: validation of the self-reporting questionnaire and Edinburgh Postnatal Depression Scale. J Affect Disord. 2008;108(3):251262. CrossRef. Medline

11. Harpham T, Huttly S, De Silva MJ, Abramsky T. Maternal mental health and child nutritional status in four developing countries. J Epidemiol Community Health. 2005;59(12):1060-1064. CrossRef. Medline
12. Gebeyehu W, Birhanu D, Shattuck D, Getachew $Y$, Bristow $H$, Baumgartner J, et al. Amhara regional assessment of postpartum family planning uptake. Addis Ababa (Ethiopia): Ministry of Health; 2013. Co-published by FHI 360 .

13. World Health Organization (WHO). A user's guide to the selfreporting questionnaire (SRQ). Geneva: WHO; 1994. Available from: http://whqlibdoc.who.int/hq/1994/WHO_MNH_PSF_ 94.8.pdf

14. Stewart RC, Umar E, Tomenson B, Creed F. Validation of screening tools for antenatal depression in Malawi-a comparison of the Edinburgh Postnatal Depression Scale and Self Reporting Questionnaire. J Affect Disord. 2013;150(3):10411047. CrossRef. Medline

15. Alem A, Kebede D, Woldesemiat G, Jacobsson L, Kullgren G. The prevalence and socio-demographic correlates of mental distress in Butajira, Ethiopia. Acta Psychiatr Scand. 1999;100:48-55. CrossRef. Medline

16. Youngmann R, Zilber N, Workneh F, Giel R. Adapting the SRQ for Ethiopian populations: a culturally-sensitive psychiatric screening instrument. Transcult Psychiatry. 2008;45(4):566589. CrossRef. Medline

17. Hailemariam S, Tessema F, Asefa M, Tadesse H, Tenkolu G. The prevalence of depression and associated factors in Ethiopia: findings from the National Health Survey. Int J Ment Health Syst. 2012;6(1):23. CrossRef. Medline

18. Harpham T, Reichenheim M, Oser R, Thomas E, Hamid N, Jaswal $S$, et al. Measuring mental health in a cost-effective manner. Health Policy Plan. 2003;18(3):344-349. CrossRef. Medline

19. Fekadu A, Medhin G, Selamu M, Hailemariam M, Alem A, Giorgis TW, et al. Population level mental distress in rural Ethiopia. BMC Psychiatry. 2014;14(1):194. CrossRef. Medline

20. Deyessa N, Berhane Y, Alem A, Hogberg U, Kullgren G. Depression among women in rural Ethiopia as related to socioeconomic factors: a community-based study on women in reproductive age groups. Scand J Public Health. 2008;36(6):589-597. CrossRef. Medline

21. Patel V, Belkin GS, Chockalingam A, Cooper J, Saxena S, Unützer J. Grand challenges: integrating mental health services into priority health care platforms. PLoS Med. 2013;10(5):e1001448. CrossRef. Medline

22. World Health Organization (WHO). mhGAP intervention guide for mental, neurological and substance use disorders in nonspecialized health settings. Geneva: WHO; 2010. Available from: http://www.who.int/mental_health/publications/ mhGAP_intervention_guide/en/

\section{Peer Reviewed}

Received: 2014 Jul 22; Accepted: 2014 Nov 12

Cite this article as: Baumgartner JN, Parcesepe A, Mekuria YG, Abitew DB, Gebeyehu W, Okello F, et al. Maternal mental health in Amhara region, Ethiopia: a cross-sectional survey. Glob Health Sci Pract. 2014;2(4):482-486. http://dx.doi.org/10.9745/GHSP-D-14-00119.

(c) Baumgartner et al. This is an open-access article distributed under the terms of the Creative Commons Attribution License, which permits unrestricted use, distribution, and reproduction in any medium, provided the original author and source are properly cited. To view a copy of the license, visit http://creativecommons.org/licenses/by/3.0/. When linking to this article, please use the following permanent link: http://dx.doi. org/10.9745/GHSP-D-14-00119. 